\title{
The Dendritic Complexity and Innervation of Submandibular Neurons in Five Species of Mammals
}

\author{
William D. Snider \\ Departments of Anatomy and Neurobiology, Neurology and Neurological Surgery (Neurology), Washington University \\ School of Medicine, St. Louis, Missouri 63110
}

\begin{abstract}
I have compared the dendritic complexity and innervation of homologous parasympathetic ganglion cells in several closely related species of mammals. In the smaller of these species (mouse, hamster, and rat), submandibular ganglion cells generally lack dendrites altogether and are innervated by a single axon. In the guinea pig, a somewhat larger species, these neurons possess rudimentary dendritic arbors and are innervated by 2 axons, on average. In the largest species investigated, the rabbit, submandibular ganglion cells have moderately complex dendritic arbors and receive innervation from several axons. These findings, together with a previous study of sympathetic ganglion cells in these same species (Purves and Lichtman, 1985a), indicate that relationships among neuronal morphology, convergent innervation, and animal size are widespread in the autonomic nervous system of mammals.
\end{abstract}

In an attempt to formulate principles governing the innervation of neurons in mammals, recent work in the autonomic nervous system has explored the relationship between the number of axons innervating a ganglion cell and the complexity of its dendritic arbor. Neurons without dendrites are frequently innervated by a single axon, whereas those that possess dendrites are innervated by a number of axons proportional to the number and complexity of their dendritic processes (Lichtman, 1977; Purves and Hume, 1981; Purves and Lichtman, 1985a). A further correlation noted in the sympathetic nervous system is that both dendritic complexity and number of innervating axons (convergence) increase in relation to animal size across closely related mammalian species (Purves and Lichtman, 1985a). However, the extent to which other peripheral motor systems conform to this pattern is unknown. This issue is relevant to understanding how the mammalian nervous system copes with the enormous differences in size that are manifest among different species, and to understanding how neural organization in peripheral motor systems is regulated.

The purpose of the present work was to assess the generality

\footnotetext{
Received June 24, 1986; revised Oct. 21, 1986; accepted Dec. 18, 1986.

This work was supported by Grants NS 11699 and 18629 to Dale Purves. W.D.S. was supported by the R. S. Morrison Fellowship from the Grass Foundation. I thank D. Purves and J. Lichtman for suggesting this project, and D. Purves for helpful advice throughout the course of the work. Excellent technical assistance was provided by P. Newton. Useful comments were made by C. Forehand and J. Voyvodic. I thank Sue Eads for typing the manuscript.

Correspondence should be addressed to Dr. William D. Snider, Department of Neurology, Washington University School of Medicine, 660 South Euclid Avenue Box 8111 , St. Louis, MO 63110.

Copyright (C) 1987 Society for Neuroscience $0270-6474 / 87 / 061760-09 \$ 02.00 / 0$
}

of the relationships among preganglionic convergence, dendritic complexity, and animal size. I have therefore studied neuronal morphology and innervation in a parasympathetic ganglion (the submandibular) of 5 small mammals. I show here that dendritic complexity and convergence are correlated in the submandibular ganglion and that both parameters change in rough proportion to animal weight across these species. I suggest that trophic interactions with peripheral targets may link these aspects of neural organization to animal size.

\section{Materials and Methods}

Young adult mice, hamsters, rats, guinea pigs, and rabbits at approximately the age of sexual maturity were studied. Females were used exclusively because some autonomic ganglia show significant sexual dimorphism in neuronal number and morphology (Wright and Smolen, 1983; Voyvodic, 1987). These species vary in weight over a 70 -fold range (Table 1). Submandibular gland weights also increased substantially across species, although to a lesser extent than body weights. For example, between the mouse and the rabbit, the mean submandibular gland weight increased by a factor of $12(0.08 \mathrm{gm} \pm 0.01, n=5$, to $0.98 \mathrm{gm} \pm 0.16, n=8$ ).

The submandibular ganglion is a collection of cholinergic neurons lying between the lingual nerve and the submandibular and sublingual gland ducts, as well as along the ducts themselves (Fig. 1). There are usually several groups of cells, which form individual ganglia ranging from a few to several hundred cells each. The neurons project to either the submandibular or the sublingual gland, but these classes are not anatomically distinct; I have therefore used the term "submandibular ganglia" to refer to both (however, see Kawa and Roper, 1984). The ganglia are reached by following the submandibular and sublingual gland ducts underneath the digastric and mylohyoid muscles to the point where the ducts cross the lingual nerve (see Fig. 1 and Lichtman, 1977). This basic arrangement was similar in all of the species examined.

Dendritic morphology. For the determination of dendritic morphology, animals were anesthetized with pentobarbital and perfused through the heart with a mammalian saline solution (in mM/liter: $\mathrm{Na}^{+}, 142 ; \mathrm{K}^{+}$, 5.0; $\mathrm{Ca}^{2+}, 5.0 ; \mathrm{Mg}^{2+}, 1.0 ; \mathrm{Cl}^{-}, 143.0 ; \mathrm{PO}_{4}^{-}, 0.5 ; \mathrm{HEPES}, 4.2 ;$ glucose $11.0 ; \mathrm{pH} 7.3$ at room temperature). Ganglia were removed and pinned in a lucite chamber illuminated from below through a dark-field condenser, then perfused with oxygenated saline. Neurons were impaled with triangular glass electrodes (Glass Company of America) filled with a $5 \%$ solution of HRP (Sigma type VI in $0.2 \mathrm{M}$ potassium acetate; see Purves and Hume, 1981; Hume and Purves, 1983, for details). Dye injection parameters were 3-5 $\mathrm{nA}$ at $5 \mathrm{~Hz}$ for 3-5 min.

Ganglia were placed in fixative overnight and the HRP was reacted by the pyrocatechol-phenylenediamine method (Hanker et al., 1977). Neurons were viewed at $300 \times$ in whole mount preparations (Fig. 2; see also Purves and Hume, 1981). For each cell, the number of primary dendrites and total dendritic length were determined. A primary dendrite was considered to be any process extending from the soma for more than the distance of a cell diameter. Total dendritic length and soma diameter were measured with the aid of a digitizing tablet attached to a PD11-44 computer (see Voyvodic, 1986). Forty to 50 neurons were studied in each species. 


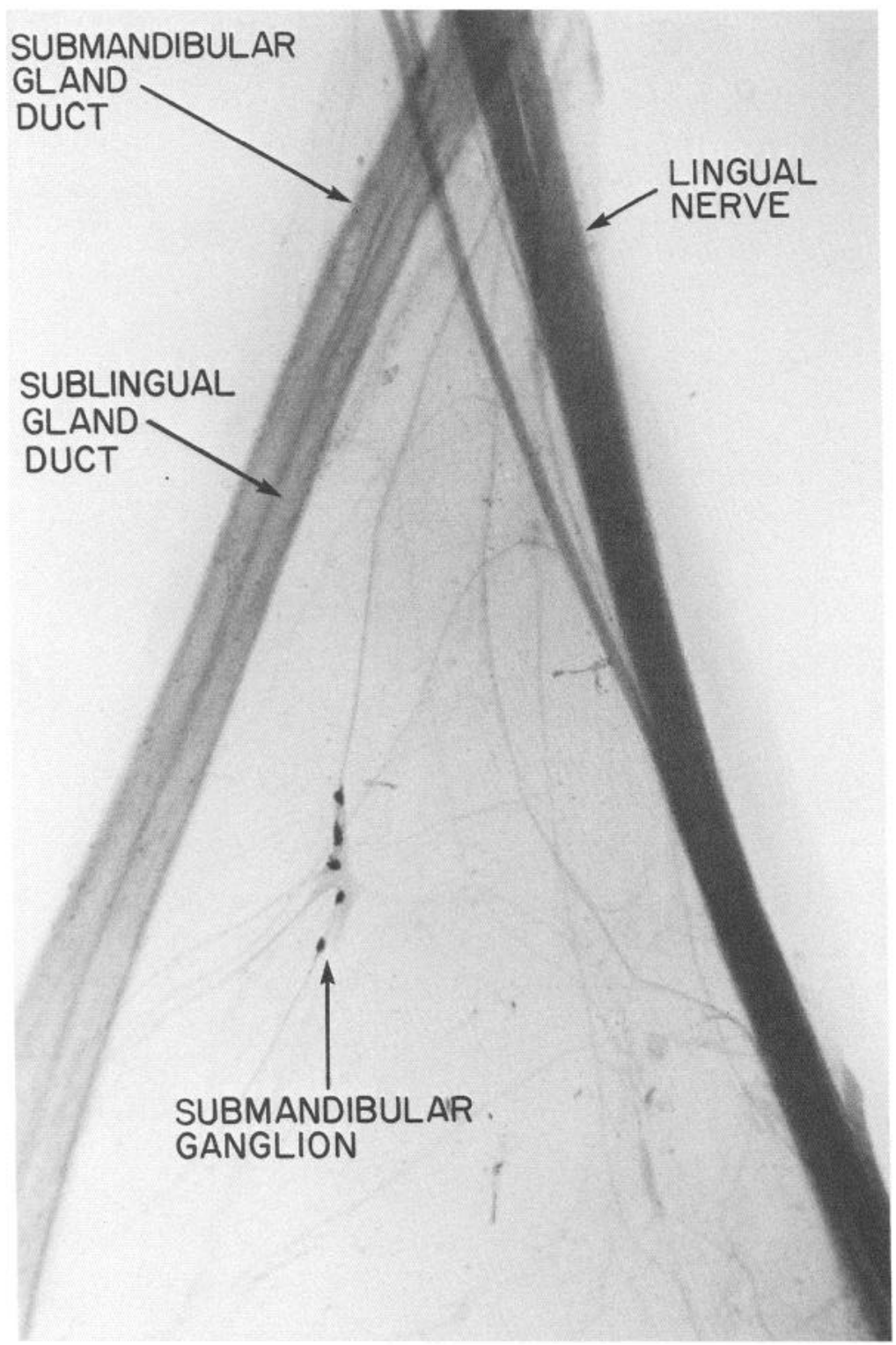

Figure 1. Low-power photomicrograph of the rat submandibular ganglion. Neurons are found in connective tissue between the lingual nerve and the submandibular and sublingual gland ducts. Five cells have been stained by intracellular injection of HRP. Other groups of cells (not shown) are distributed along the salivary ducts.

Number of innervating axons. The number of axons innervating submandibular neurons was determined by intracellular recording. A length of the lingual nerve was drawn into a suction electrode. The intensity of stimulation was gradually increased and the number of increments in the synaptic response determined (Fig. 3; for details of this technique, see Lichtman, 1977; Njå and Purves, 1977). This method may underestimate the number of axons contacting a cell, particularly when more than 6 inputs are present. The limitations have been discussed elsewhere (Lichtman, 1977; Purves and Hume, 1981). For these experiments, 5060 neurons were studied in each species.

Table 1. Dendritic complexity of submandibular neurons

\begin{tabular}{lclllr} 
Animal & Weight & $\begin{array}{l}\text { Soma diameter } \\
(\mu \mathrm{m})\end{array}$ & $\begin{array}{l}\text { No. of primary } \\
\text { dendrites }\end{array}$ & $\begin{array}{l}\text { Cells with no } \\
\text { primary } \\
\text { dendrite }(\%)\end{array}$ & $\begin{array}{l}\text { Total } \\
\text { dendritic } \\
\text { length } \\
(\mu \mathrm{m})\end{array}$ \\
\hline Mouse & 26 & 28.9 & 0 & 98 & 4 \\
Hamster & 113 & 35.6 & 0 & 95 & 15 \\
Rat & 171 & 34.3 & 0.2 & 83 & 51 \\
Guinea pig & 387 & 36.1 & 1.4 & 34 & 196 \\
Rabbit & 1885 & 37.0 & 7.8 & 0 & 1387 \\
\hline
\end{tabular}




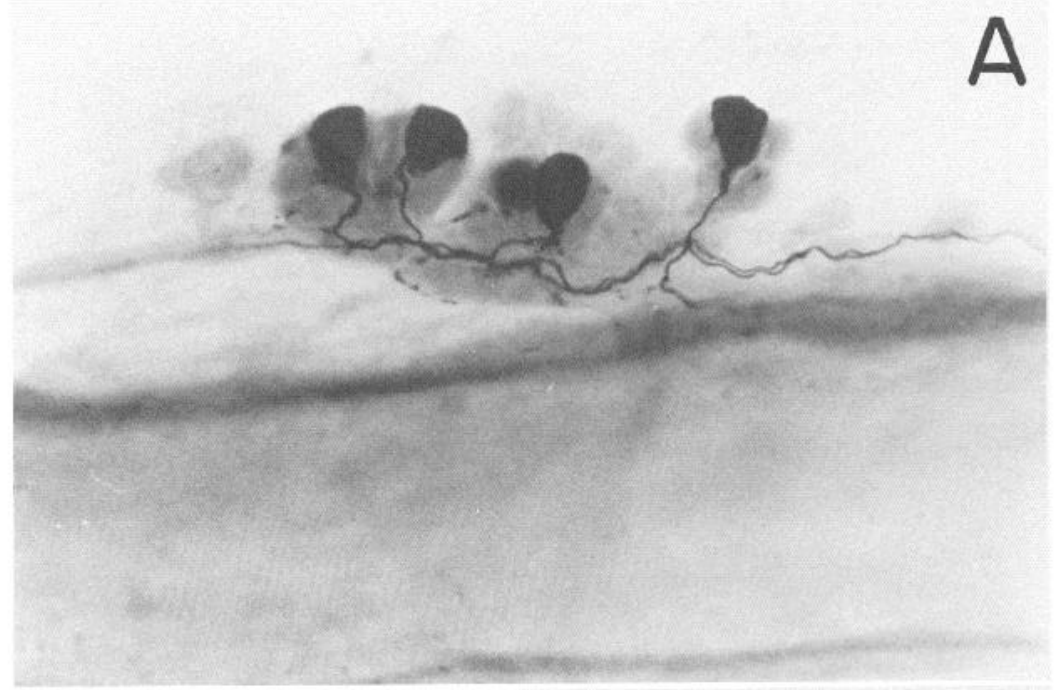

Figure 2. Photomicrographs showing examples of submandibular ganglion cells from different species, filled with HRP. $A$, Four adendritic neurons from a mouse. Axons exit the ganglion to the right to run along the salivary ducts $(b e-$ low). $B$, Two guinea pig neurons with a few short processes. $C$, Rabbit neuron with several long primary dendrites.

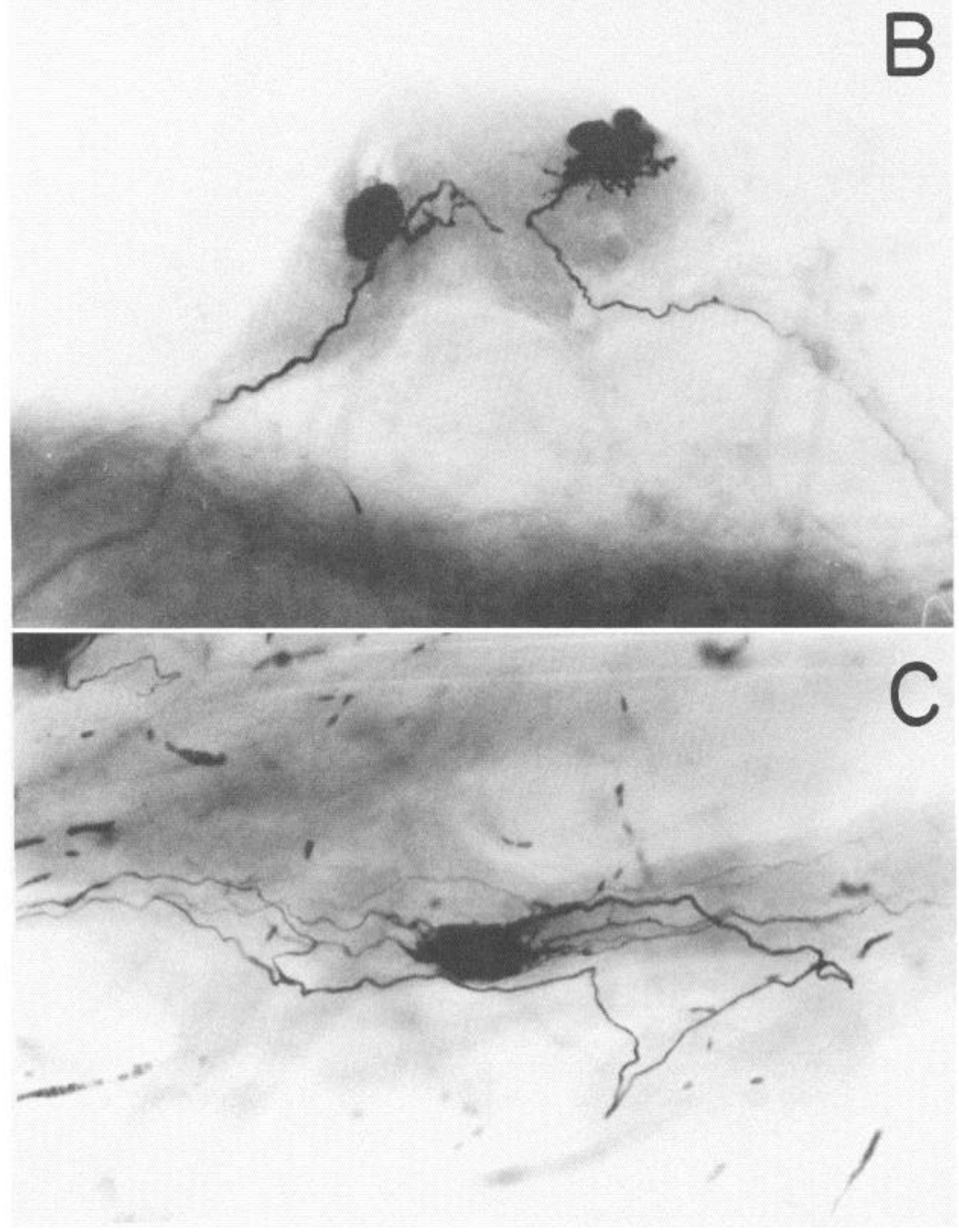

\section{Results}

Dendritic complexity

Camera lucida tracings of HRP-filled submandibular ganglion cells from all 5 species are shown in Figure 4. It is apparent that neuronal size and dendritic complexity increase in parallel with increasing animal size (see also Table 1).

In the smaller species (mouse, hamster, and rat), neurons were usually adendritic. There were, however, some subtle differences among these animals. For example, only 1 of 43 mouse and 2 

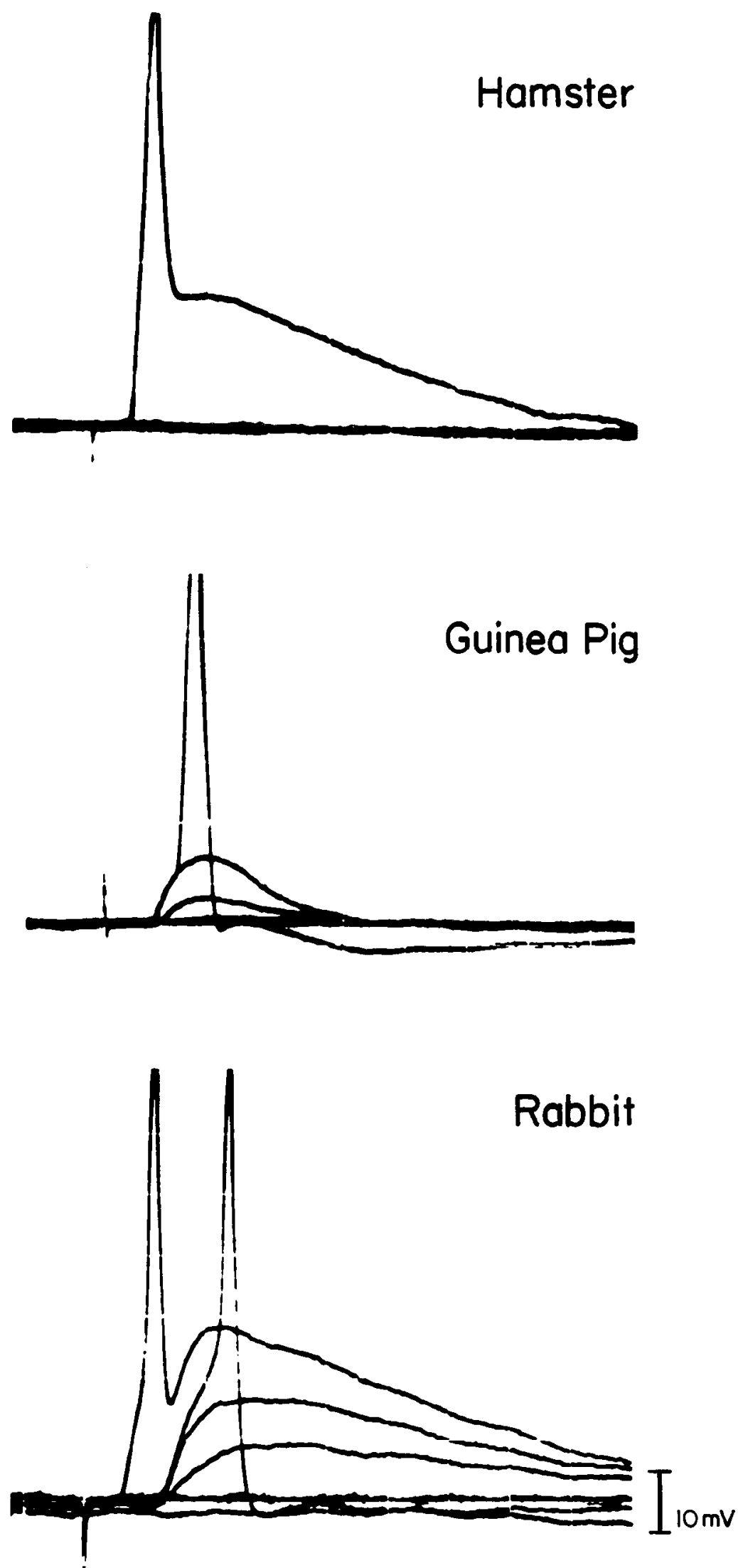

Figure 3. Intracellular responses to graded lingual nerve stimulation in different species. In these representative examples, the hamster neuron responded with 1 excitatory postsynaptic potential suprathreshold for initiating an action potential, indicating that there is a single axonal contact. The guinea pig neuron shows 2 subthreshold and 1 suprathreshold response, indicating 3 axonal inputs. The rabbit neuron responded with 2 subthreshold and 2 suprathreshold synaptic potentials, indicating contact by 4 separate axons. of 44 hamster neurons had a process of sufficient length to qualify as a primary dendrite (approximately $35 \mu \mathrm{m}$ ). However, 8 of 46 rat neurons had one or more primary dendrites. In addition, the total length of the processes present increased across these species (Table 1). Finally, rat neurons sometimes exhibited short cytoplasmic extensions from the cell body (perhaps representing incipient dendrites), whereas the surfaces of mouse and hamster neurons were usually smooth (Fig. 5). 


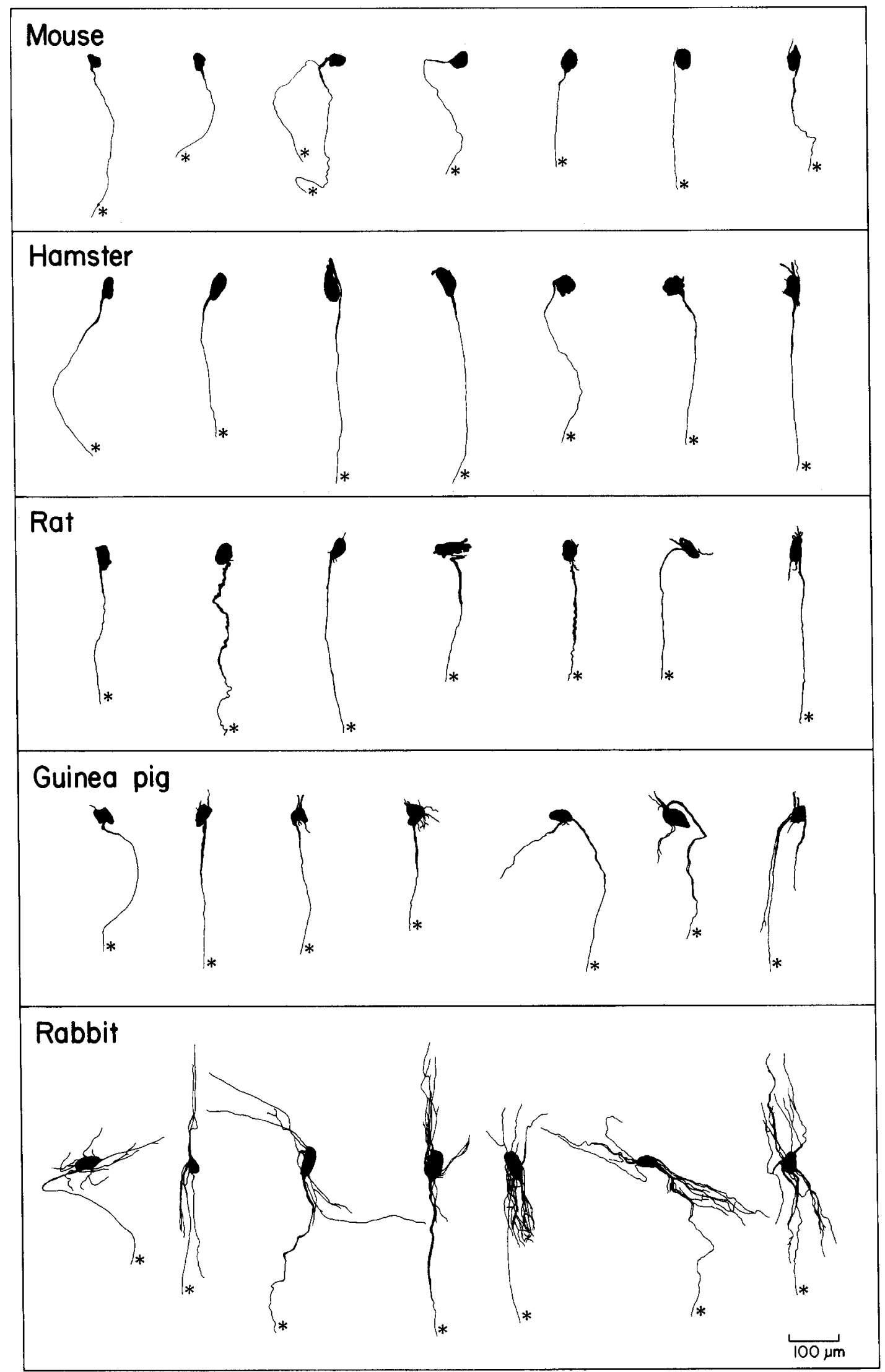

Figure 4. Camera lucida drawings of HRP-filled submandibular ganglion cells in the 5 species studied. Every seventh neuron was selected from a group of about 45 arranged in order of increasing total dendritic length (or cell diameter for neurons without dendrites). The axon is denoted by an asterisk. Although neurons from each species generally look somewhat different, a range of morphologies is present and there is some overlap between species. For example, the most complex guinea pig neurons have a greater total dendritic length than the least complex rabbit neurons. Overall there is a substantial increase in the complexity of dendritic arbors across species. 


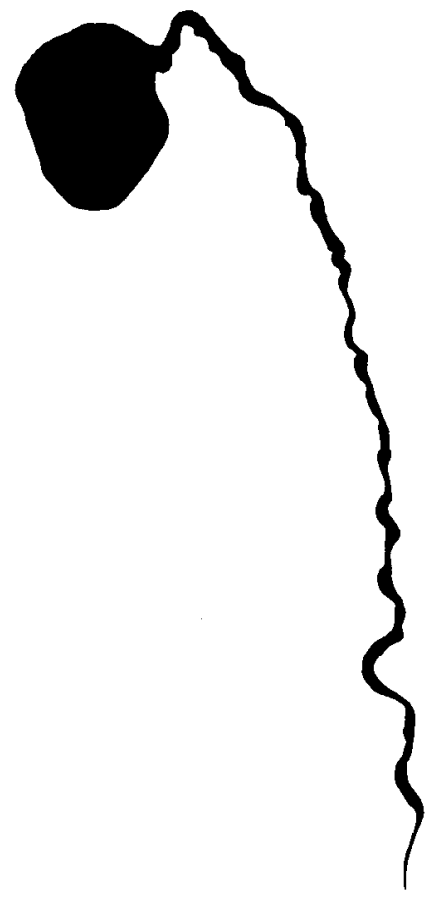

MOUSE
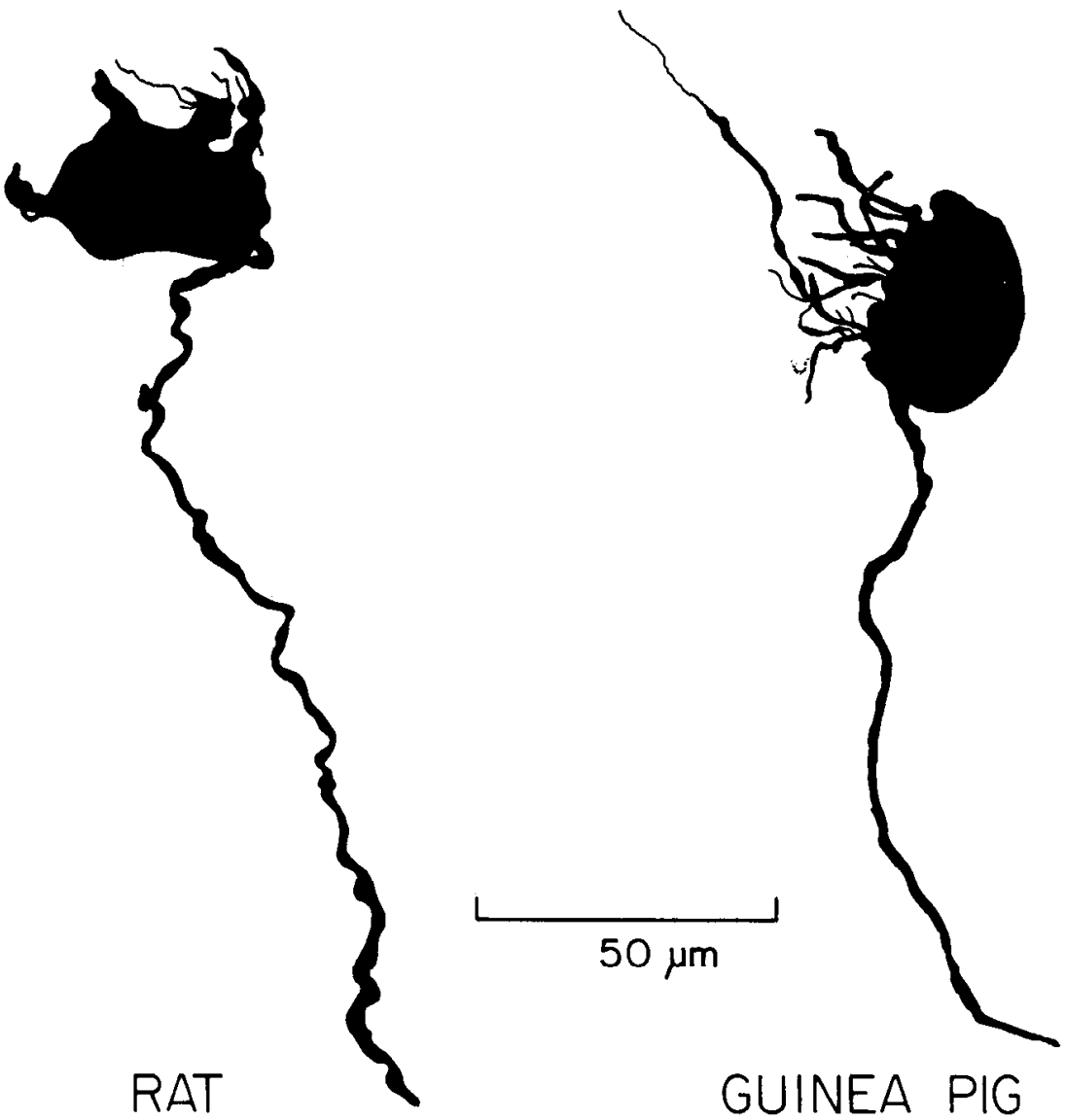

Figure 5. High-power camera lucida drawings of representative mouse, rat, and guinea pig neurons showing details of cell body configurations. Somata of mouse submandibular ganglion cells are almost always smooth, whereas rat cells often have short cytoplasmic extensions (about $25 \%$ of cells). Multiple short processes that did not qualify as primary dendrites extended even more frequently from the somata of guinea pig submandibular neurons (about 33\% of cells).

In guinea pigs, most neurons had at least rudimentary dendritic arbors, with up to 5 primary dendrites (1.4 on average; Table 1). Many guinea pig neurons also had small processes extending from the soma that did not reach the necesary lengths to qualify as primary dendrites (Fig. 5). The limited nature of these dendritic arbors is underscored by the fact that the mean total dendritic length was $196 \mu \mathrm{m}$, less than $10 \%$ of the value for guinea pig superior cervical ganglion cells at a comparable age (Purves and Lichtman, 1985a).

The most complex submandibular ganglion cells were found in the rabbit, the largest of the species examined. Rabbit neurons had 2-14 primary dendrites (mean, 7.8) and a mean total dendritic length of $1387 \mu \mathrm{m}$. No adendritic neurons were encountered. Rabbit submandibular neurons were also considerably less complex than rabbit superior cervical ganglion cells, which had a mean total dendritic length of $4143 \mu \mathrm{m}$ (Purves and Lichtman, 1985a).

\section{Convergence}

The number of axons innervating individual submandibular ganglion cells is shown in Figure 6. Neurons in the smaller species (mouse, hamster, and rat) generally received innervation from a single axon. However, a significant number of neurons were also contacted by a second, smaller input. These secondary inputs were suprathreshold for initiating an action potential in only 1 of 39 mouse and hamster neurons that received multiple innervation. Similar findings in the rat have been reported by Lichtiman (1977, 1980).

In the guinea pig, submandibular neurons were contacted by 1-4 axons (mean, 2.1), and there was less disparity in the sizes of different inputs. Guinea pig neurons were driven to threshold by 2 or more inputs in 13 of 47 instances (28\%) of multiple innervation.

Rabbit neurons were always multiply innervated, receiving synapses from 3-8 separate axons. These neurons had an average of 5.3 inputs. This value may be a substantial underestimate because of the difficulty in resolving more than 5 or 6 inputs by the methods employed here. Rabbit neurons were driven to threshold by 2 or more inputs in 16 of 37 instances $(43 \%)$ in which this information was recorded.

\section{Discussion}

Generality of the correlation between dendritic complexity and preganglionic convergence in the autonomic nervous system

Comparisons of submandibular neurons in these different species show that dendritic complexity and preganglionic convergence are closely associated. In species where neurons generally lack dendrites, submandibular ganglion cells are innervated by a single axon, or sometimes by 1 large and a second, smaller input. In the guinea pig, where submandibular ganglion cells possess rudimentary arbors, these neurons are innervated by 2 axons on average. In the rabbit, submandibular neurons have rela- 

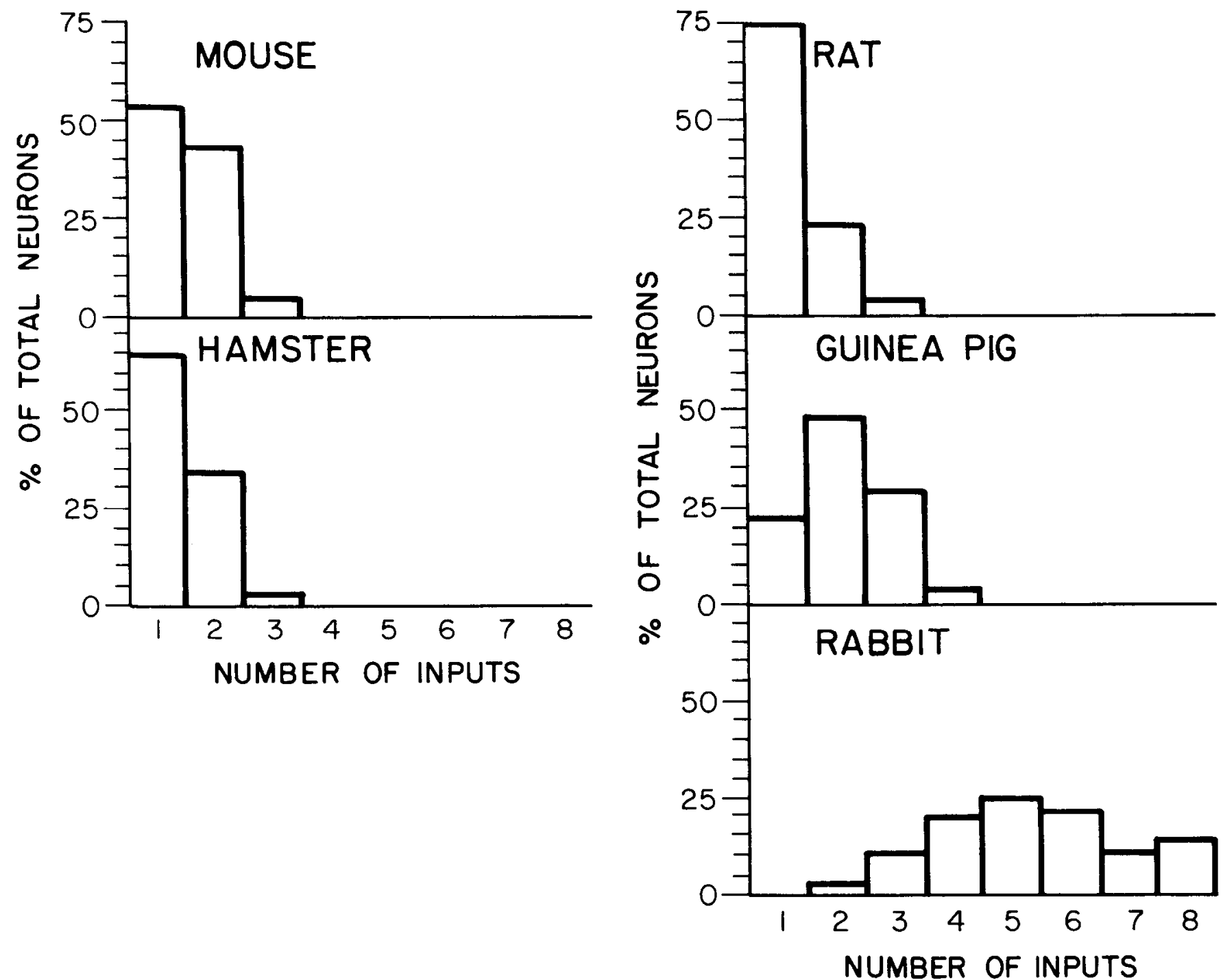

Figure 6. Histograms of the number of inputs to submandibular ganglion cells in the 5 species examined. About 55 neurons were studied in each species. Data from the rat are redrawn from Lichtman (1977).

tively complex arbors and receive innervation from 2 to 8 preganglionic axons.

These findings support an accumulating body of evidence that indicates that dendritic complexity and preganglionic convergence are tightly linked throughout the autonomic nervous systems of mammals. Similar results have been obtained for neurons of diverse geometry within individual parasympathetic and sympathetic ganglia (Purves and Hume, 1981; Purves and Lichtman, 1985a), for different autonomic ganglia in a single species (cf. Lichtman, 1977; Wigston, 1983; Purves and Lichtman, 1985a), and for sympathetic ganglia in several closely related species (Purves and Lichtman, 1985a). To date, no exceptions to this principle have been encountered. Although the reasons for the correlation between dendritic complexity and convergence are not entirely clear, it appears that dendritic complexity determines convergence, and not vice versa (Hume and Purves, 1981, 1983; Forehand and Purves, 1984; Forehand, 1985; Purves and Lichtman, 1985b; Voyvodic, 1987).

\section{Relationship between dendritic complexity and animal size}

The results reported here also show that the increased dendritic complexity (and convergent innervation) of submandibular gan- glion cells is associated with increasing animal size across these species. In the smaller species, neurons generally lacked dendrites, although such processes as were present increased in length between the mouse and rat. In guinea pigs, which are roughly twice the size of rats, most submandibular neurons had rudimentary arbors. Submandibular ganglion cells in rabbits (about 5 times as large as guinea pigs) had moderately complex arbors.

These findings can be compared with corresponding results from 3 other parts of the nervous system. Sympathetic neurons in the species studied here exhibit similar differences in dendritic complexity and convergence in relation to animal size (Purves and Lichtman, 1985a). For example, between the mouse and rabbit, there is an 8-fold difference in total dendritic length, and preganglionic convergence increases by a factor of 3 . In the ciliary ganglion, measurements of these parameters have been made in the mouse and rabbit (see Purves and Hume, 1981; Jackson, 1986; see also Wigston, 1983). The mean total dendritic length of ciliary neurons increases substantially between these species [mouse, $219 \mu \mathrm{m}$ (Jackson, 1986); rabbit, $558 \mu \mathrm{m}$ (Purves and Hume, 1981)]. The numbers of primary dendrites (mouse, 1.8; rabbit, 2.4) and numbers of innervating axons 
(mouse, 2.9; rabbit, 2.6) apparently differ very little. However, information about the morphology and innervation of ciliary neurons in other species is not yet available. Finally, although studies correlating geometry and innervation have not been performed in the central nervous system, the dendritic complexity of homologous pyramidal neurons in cerebral cortex has been found to increase in relation to animal size in several of the species studied here (Bok, 1959).

\section{Reasons for a relationship between animal size and neural organization}

Although the correlation of dendritic complexity and preganglionic convergence with animal size across these species is clear, it is open to several possible interpretations. One possibility is that dendritic morphology is an intrinsic (i.e., largely genetic) property of the submandibular neurons of the different species. For example, experiments in which transplanted body parts assume characteristics of the donor and not the host suggest species-specific mechanisms for determining the characteristics of certain tissues (reviewed in Spemann, 1938). That dendritic morphology may be partly determined by such mechanisms has been postulated because embryonic neurons in culture often develop morphologies characteristic of their neuronal class (Banker and Cowan, 1977; Wakshull et al., 1979; Kriegstein and Dichter, 1985; Honig and Hume, 1986). It is unlikely, however, that intrinsic neuronal properties fully account for the cross-species differences in morphology and innervation observed here. Dendritic growth and synaptogenesis in autonomic ganglia begin relatively late in the embryonic period and proceed well into postnatal life (Smolen and Raisman, 1980; Rubin, 1985a, b; Snider, 1986a; Voyvodic, 1987). Both processes are strongly affected by epigenetic influences that operate in all mammalian species (for example, the availability of trophic molecules and levels of neural activity). Indeed, in quail-chick chimeras, where the effects of cross-species transplantation can be tested directly, neural crest-derived cells from the 2 species respond to epigenetic influences in exactly the same manner (Le Douarin, 1982).

Of the differences among these species more likely to account for the present results, the most striking is animal size. Since neuronal number in general does not keep pace with increasing body weight (Ebbesson, 1968; Purves et al., 1986), there must be some mechanism that allows peripheral motor systems in different species to activate targets that are enormously different in mass and extent. Changing the degree of preganglionic branching and the level of ganglion cell activity through regulation of preganglionic convergence could be one way that the peripheral autonomic nervous system adjusts to differences in animal size (Purves et al., 1986).

The correlation between dendritic complexity and convergence and animal size also suggests a way in which peripheral neural organization may be regulated. There is substantial evidence that dendritic arbors, like other properties of peripheral ncurons, arc influenced by trophic interactions with their targets. When motor neurons or sympathetic ganglion cells are disconnected from peripheral targets by axotomy, their dendrites exhibit morphological changes and arbors retract in total extent (Grant, 1965; Sumner and Watson, 1971; Purves, 1975; Yawo, 1986). These effects are reversed upon reinnervation (Sumner and Watson, 1971; H. Yawo, unpublished observations). Furthermore, during development, dendrites of superior cervical ganglion cells continue to grow as long as body weight increases, far beyond what is usually considered the developmental period (Voyvodic, 1987). Finally, administration of a target-derived molecule, nerve growth factor, results in a substantial acceleration of the dendritic growth of sympathetic neurons in young animals (Snider, 1986b). Since trophic support seems likely to bear some relationship to target mass, these several observations suggest a mechanism that may relate the dendritic complexity (and innervation) of ganglion cclls to animal size.

\section{References}

Banker, G. A., and W. M. Cowan (1979) Further observations on hippocampal neurons in dispersed cell culture. J. Comp. Neurol. 187: $469-494$.

Bok, S. T. (1959) Histonomy of the Cerebral Cortex, Elsevier, Amsterdam.

Ebbesson, S. O. E. (1968) Quantitative studies of superior cervical sympathetic ganglia in a variety of primates including man. $\mathrm{I}$. The ratio of preganglionic fibers to ganglionic neurons. J. Morphol. 124: 112-132.

Forehand, C. J. (1985) Density of somatic innervation of mammalian ganglion cells is inversely related to dendritic complexity and preganglionic convergence. J. Neurosci. 5: 3403-3408.

Forehand, C. J., and D. Purves (1984) Regional innervation of the rabbit ciliary ganglion cells by the terminals of preganglionic axons. J. Neurosci. 4: 1-12.

Grant, G. (1965) Degenerative changes in dendrites following axonal transection. Experientia 21: 722.

Hanker, J. S., P. E. Yates, C. B. Metz, and A. Rustioni (1977) A new specific, sensitive, and non-carcinogenic reagent for the demonstration of horseradish peroxidase. Histochem. J. 9: 789-792.

Honig, M. G., and R. I. Hume (1986) Fluorescent carbocyanine dyes allow living neurons of identified origin to be studied in long-term cultures. J. Cell Biol. 103: 171-187.

Hume, R. I., and D. Purves (1981) Geometry of neonatal neurones and the regulation of synapse elimination. Nature 293: 469-471.

Hume, R. I., and D. Purves (1983) Apportionment of the terminals from single preganglionic axons to target neurones in the rabbit ciliary ganglion. J. Physiol. (Lond.) 338: 259-275.

Jackson, P. D. (1986) Innervation of the iris by individual parasympathetic axons in the adult mouse. J. Physiol. (Lond.) 378: 485-495.

Kawa, K., and S. Roper (1984) On the two subdivisions and intrinsic synaptic connexions in the submandibular ganglion of the rat. J. Physiol. (Lond.) 346: 301-320.

Kriegstein, A. R., and M. A. Dichter (1983) Morphological classification of rat cortical neurons in cell culture. J. Neurosci. 3: 16431647.

Le Douarin, N. M. (1982) The Neural Crest, Cambridge U. P., New York.

Lichtman, J. W. (1977) The reorganization of synaptic connexions in the rat submandibular ganglion during postnatal development. J. Physiol. (Lond.) 273: 155-177.

Lichtman, J. W. (1980) On the predominantly single innervation of submandibular ganglion cells in the rat. J. Physiol. (Lond.) 302: 121130.

Njå, A., and D. Purves (1977) Specific innervation of guinea-pig superior cervical ganglion cells by preganglionic fibres arising from different levels of the spinal cord. J. Physiol. (Lond.) 264: 565-583.

Purves, D. (1975) Functional and structural changes in mammalian sympathetic neurons following interruption of their axons. J. Physiol. (Lond.) 252: 429-463.

Purves, D., and R. I. Hume (1981) The relation of postsynaptic geometry to the number of presynaptic axons that innervate autonomic ganglion cells. J. Neurosci. 1: 441-452.

Purves, D., and J. W. Lichtman (1985a) Geometrical differences among homologous neurons in mammals. Science 228: 298-302.

Purves, D., and J. W. Lichtman (1985b) Principles of Neural Development, pp. 271-301, Sinauer, Sunderland, MA.

Purves, D., E. Rubin, W. D. Snider, and J. W. Lichtman (1986) Relation of animal size to convergence, divergence and neuronal number in peripheral sympathetic pathways. J. Neurosci. 6: 158-163.

Rubin, E. (1985a) Development of the rat superior cervical ganglion: Ganglion cell maturation. J. Neurosci. 5: 675-684. 
Rubin, L. (1985b) Development of the rat superior cervical ganglion: Initial stages of synapse formation. J. Neurosci. 5: 697-704.

Smolen, A., and G. Raisman (1980) Synapse formation in the rat superior cervical ganglion during normal development and after deafferentation. Brain Res. 181: 315-323.

Snider, W. D. (1986a) Rostrocaudal differences in dendritic growth and synaptogenesis in rat sympathetic chain ganglia. J. Comp. Neurol 244: 245-253.

Snider, W. D. (1986b) The effect of nerve growth factor on the development of dendritic arbors in the rat superior cervical ganglion. Soc. Neurosci. Abstr. 12: 1098.

Spemann, H. (1938) Embryonic Development and Induction, Yale U. P., New Haven, CT.

Sumner, B. E. H., and W. E. Watson (1971) Retraction and expansion of the dendritic tree of motor neurons of adult rats induced in vivo. Nature 233: 273-275.

Voyvodic, J. (1986) A general purpose image processing language
(IMAGR) facilitates visualizing neuronal structures in fixed tissucs and in vivo. Soc. Neurosci. Abstr. 12: 390.

Voyvodic, J. (1987) Development and regulation of dendrites in the rat superior cervical ganglion: Influence of preganglionic innervation. J. Neurosci. 7: 904-912.

Wakshull, E., M. I. Johnson, and H. Burton (1979) Postnatal rat sympathetic neurons in culture. I. A comparison with embryonic neurons. J. Neurophysiol. 42: 1410-1425.

Wigston, D. J. (1983) Maintenance of cholinergic neurones and synapses in the ciliary ganglion of aged rats. J. Physiol. (Lond.) 344: 223 231 .

Wright, L. L., and A. J. Smolen (1983) Neonatal testosterone treatment increases neuron and synapse numbers in male rat superior cervical ganglion. Dev. Brain Res. 8: 145-153.

Yawo, H. (1986) Geometrical changes of mouse sympathetic ganglion cells after axotomy. Soc. Neurosci. Abstr. 12: 1105. 